Case Report

\title{
A Fatal Case of Congenital Langerhans Cell Histiocytosis with Disseminated Cutaneous Lesions in a Premature Neonate
}

\author{
Michio Inoue, ${ }^{1,2}$ Yoko Tomita, ${ }^{1}$ Tsuyoshi Egawa, ${ }^{1}$ Tomoaki Ioroi, ${ }^{1}$ \\ Masaaki Kugo, ${ }^{1}$ and Shinsaku Imashuku ${ }^{3}$ \\ ${ }^{1}$ Department of Pediatrics, Japanese Red Cross Society Himeji Hospital, Himeji, Hyogo 670-8547, Japan \\ ${ }^{2}$ Department of Child Neurology, National Center Hospital, National Center of Neurology and Psychiatry, Tokyo 187-8551, Japan \\ ${ }^{3}$ Department of Laboratory Medicine, Uji-Tokushukai Medical Center, Uji, Kyoto 611-0042, Japan
}

Correspondence should be addressed to Shinsaku Imashuku; shinim95@mbox.kyoto-inet.or.jp

Received 3 August 2016; Revised 21 September 2016; Accepted 28 September 2016

Academic Editor: Bernhard Resch

Copyright (C) 2016 Michio Inoue et al. This is an open access article distributed under the Creative Commons Attribution License, which permits unrestricted use, distribution, and reproduction in any medium, provided the original work is properly cited.

Background. The outcome of neonates with congenital cutaneous Langerhans cell histiocytosis (LCH) is variable. Observations. We report a case of $\mathrm{LCH}$ in a female premature neonate born at 33-week gestation. She had disseminated cutaneous lesions, which consisted of hemorrhagic papules and vesicles, with sparse healthy skin areas, and the hands and feet were contracted with scarring and blackened. She was in respiratory failure although no apparent pulmonary or bone lesions on X-rays were noted. Skin biopsy confirmed a diagnosis of LCH due to observation of CDla ${ }^{+}$Langerhans cells, which lacked expression of E-cadherin and CD56. The patient died 57 hours after birth. Conclusions. Based on this case and the literature survey, the outcome of premature babies with congenital cutaneous LCH lesions is noted to be unfavorable, with the majority of such cases suffering from multisystem disease.

\section{Introduction}

Langerhans cell histiocytosis (LCH) is characterized by lesions that include $\mathrm{CD1a}{ }^{+} \mathrm{CD} 207^{+}$dendritic cells, along with inflammatory cell infiltrates. Molecular analysis clarified that $\mathrm{LCH}$ arises from pathological activation of the mitogenactivated protein kinase pathway in myeloid precursors [1]. In particular, the BRAF V600E mutation in the gene encoding serine/threonine-protein kinase B-raf has been identified in $\sim 50-60 \%$ of patients with LCH [2]. The clinical features of LCH range from localized, single-organ lesions to multifocal, multiorgan lesions. These lesions can either regress spontaneously or progress aggressively; thus, $\mathrm{LCH}$ can have a range of outcomes that vary in severity from benign to fatal [3]. Fetal and neonatal LCH are approximately equally divided into two groups: $\mathrm{LCH}$ limited to skin and $\mathrm{LCH}$ involving multiple organs [4]. Congenital LCH that is limited to cutaneous lesions is generally thought to be clinically benign, with a good prognosis [5], but rare cases have a poor outcome $[6,7]$. Notably, congenital cutaneous LCH in preterm babies (born before 37-week gestation) is a severe, systemic disease that usually causes death in utero or after delivery [8-12]. In some premature neonates with $\mathrm{LCH}$, lethal hydrops fetalis may develop [8,9]. Here, we report a fatal case of congenital LCH in a prematurely born female neonate with disseminated cutaneous lesions resembling severe burns, but with no apparent pulmonary or bone lesions.

\section{Case Report}

The mother of the patient was 33-year-old, gravida 2, and para 2, and the pregnancy was uneventful until 32-week gestation when she had a threatened premature labor and was admitted to a maternity hospital. She gave birth by vaginal delivery at 33-week and 3-day gestation. Fetal ultrasonography did not reveal any specific abnormalities, and myocardial contractility was assessed as normal by echocardiography. The mother, who was negative for toxoplasma, chlamydia, rubella, human papilloma virus, syphilis, and human $\mathrm{T}$ cell leukemia virus type 1 , had been treated with flomoxef 1 week prior to delivery because of inflammatory 


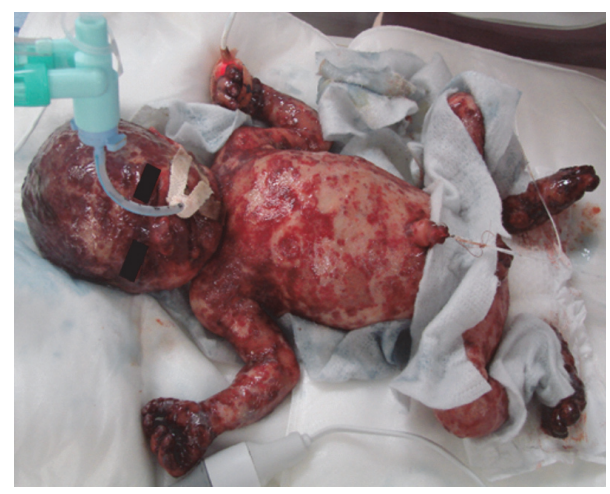

FIGURE 1: Photograph of the patient, showing extensive disseminated vesiculopapular cutaneous lesions. Hands and feet were contracted and blackened.

signs (white blood cell count (WBC), 10,540/ $\mu \mathrm{L}$, and Creactive protein (CRP) level, $1.51 \mathrm{mg} / \mathrm{dL}$ ). The newborn baby weighed 1,706 g and had Apgar scores of 8 at $1 \mathrm{~min}$ and 8 at $5 \mathrm{~min}$. At birth, she was noted to have disseminated cutaneous lesions consisting of hemorrhagic papules and vesicles on the scalp, face, trunk, and extremities. Soon after birth, the baby was not anemic but showed hypoproteinemia (total protein, $3.4 \mathrm{~g} / \mathrm{dL}$; albumin, $2.2 \mathrm{~g} / \mathrm{dL}$ ) and respiratory failure. She was immediately intubated and transferred to our hospital. When the patient arrived the following were noted: temperature, $34.7^{\circ} \mathrm{C}$; heart rate, 126 beats $/ \mathrm{min} ; \mathrm{SpO}_{2}, 100 \%$ $\left(\mathrm{FiO}_{2}\right.$ 0.25); and blood pressure, $44 / 34 \mathrm{mmHg}$. Laboratory data revealed the following: $\mathrm{WBC}, 7,000 / \mu \mathrm{L}$; hemoglobin, $15.1 \mathrm{~g} / \mathrm{dL}$; platelet count, $97,000 / \mu \mathrm{L}$; total protein, $3.2 \mathrm{~g} / \mathrm{dL}$; albumin, $1.9 \mathrm{~g} / \mathrm{dL}$; aspartate aminotransferase, $30 \mathrm{U} / \mathrm{L}$; alanine transaminase, $8 \mathrm{U} / \mathrm{L}$; total bilirubin, $7.1 \mathrm{mg} / \mathrm{dL}$; blood urea nitrogen, $11.1 \mathrm{mg} / \mathrm{dL}$; creatinine, $0.61 \mathrm{mg} / \mathrm{dL}$; sodium, $145 \mathrm{mEq} / \mathrm{L}$; potassium, $4.3 \mathrm{mEq} / \mathrm{L}$; calcium, $8.8 \mathrm{mg} / \mathrm{dL}$; CRP, $0.76 \mathrm{mg} / \mathrm{dL} ; \operatorname{IgG}, 245 \mathrm{mg} / \mathrm{dL} ; \operatorname{IgA}, 0 \mathrm{mg} / \mathrm{dL} ; \mathrm{IgM}, 4 \mathrm{mg} / \mathrm{dL}$; prothrombin time, 69\%; PT-INR, 1.25; activated partial thromboplastin time, $72.0 \mathrm{~s}$; fibrinogen, $238 \mathrm{mg} / \mathrm{dL}$; fibrin degradation products, $23 \mu \mathrm{g} / \mathrm{mL}$; D-dimer, $10.0 \mu \mathrm{g} / \mathrm{mL}$; and antithrombin, $25 \%$. On admission, the baby's skin had the appearance of severe burns, with widespread hemorrhagic papules and vesicles and sparse healthy skin. In particular, the hands and feet were contracted with scarring and blackened (Figure 1). Chest X-ray and bone scans revealed no abnormalities (data not shown). Staphylococcus species were cultured from plantar skin lesions, but no infectious agents were found in swabs taken from the oral mucosa. Blood cultures were not performed. The baby was given infusion fluid along with ampicillin, intravenous immunoglobulin, and albumin. Skin lesions were managed with procedures used for extensive burn care. Biopsy specimens from skin lesions were taken on Day 1 of admission. The results showed histiocytic cell infiltration in the epidermis and dermis as well as under the stratum corneum with proliferation of $\mathrm{S} 100^{+}, \mathrm{CDla}^{+}$ Langerhans cells, leading to a diagnosis of LCH (Figure 2). These cells did not express E-cadherin or CD56. Detection of the BRAF V600E mutation was attempted with DNA extracted from paraffin-embedded sections of skin biopsy specimens, but the result was negative (data not shown). The patient did not respond well to intensive therapeutic measures under respiratory care, including ceftriaxone, fluconazole, and catecholamine, as well as attempted correction of metabolic acidosis. On Day 2, she developed hypovolemic shock and cardiopulmonary arrest. She was resuscitated and received exchange transfusion but died 57 hours after birth. No autopsy was obtained.

\section{Discussion}

Differential diagnosis of neonatal skin filtrates includes various malignancies [14]. LCH should be considered in the differential diagnosis of widespread cutaneous lesions in neonates. This prematurely born female neonate was diagnosed with disseminated cutaneous LCH lesions. The cutaneous lesions resembled severe burns, with sparse healthy skin areas and the blackened eruptions in the hands and feet were similar to those described previously [11] in a case with purpuric/necrotic papules, which were most prominent on the plantar feet surfaces. Although no pulmonary or bone lesions were apparent on X-rays on her admission, she was in respiratory failure and since the patient lived only for $<3$ days, no CT scan was carried out to examine the detailed lung lesions. Also, considering her hypoalbuminemia and thrombocytopenia which may indicate the risk organ involvement, it is possible that this neonate could be a case of multisystem disease. Although her LCH presumably developed in utero, the results of fetal ultrasonography were normal and did not indicate hydrops fetalis. The likely cause of death was hypovolemic shock as is often seen in patients with extensive burns and pulmonary failure. Unfortunately, because no autopsy was permitted, we could not confirm histopathologically if she actually had multisystemic LCH with involvement of organs other than the skin.

Although cutaneous lesions associated with $\mathrm{LCH}$ in infants are often self-healing [5], evidence suggests that the occurrence of these lesions in association with premature birth is not benign [8-12] (Table 1). As summarized, in this case and in six other cases identified in the literature, the majority of premature neonates with congenital cutaneous LCH lesions had a multisystem disease and poor outcome (Table 1). These poor outcomes were mostly associated with pulmonary failure or multiorgan failure, with two cases of hydrops fetalis. Skin lesions were variable, from diffuse cutaneous nodules [11], isolated vesiculopapulomacular rash [12], generalized vesicles [9], papular rash [13], and disseminated burn-like lesions (present case). Of the 2 cases associated with hydrops fetalis, one died early ( 36 hours), while the other in 12 days $[8,9]$. Exceptionally, a premature baby with cutaneous lesions at birth (albeit less extensive than in our case) survived the neonatal period [13]. The prognosis may be affected by the severity or degree of cutaneous lesions at birth, as well as by subsequent multiorgan involvement. In addition, lack of bone involvement might have played a role, because it was recently reported to be a previously 


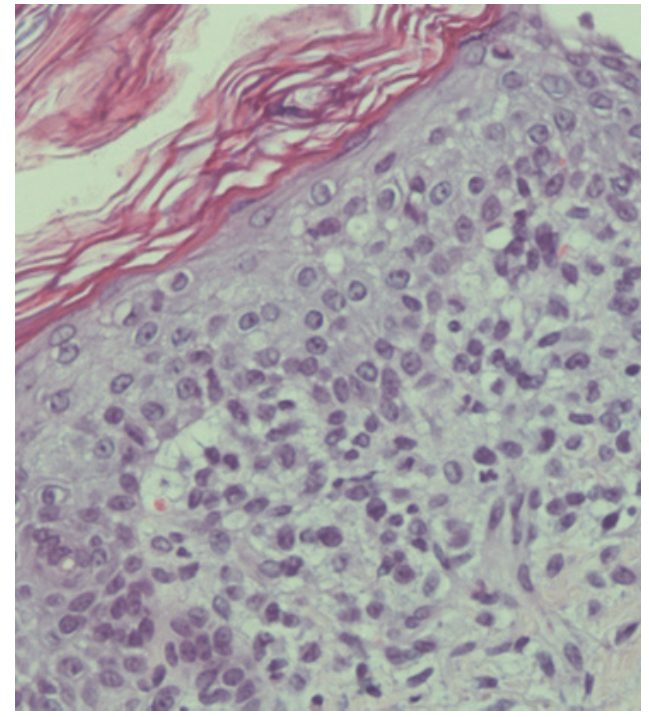

(a)

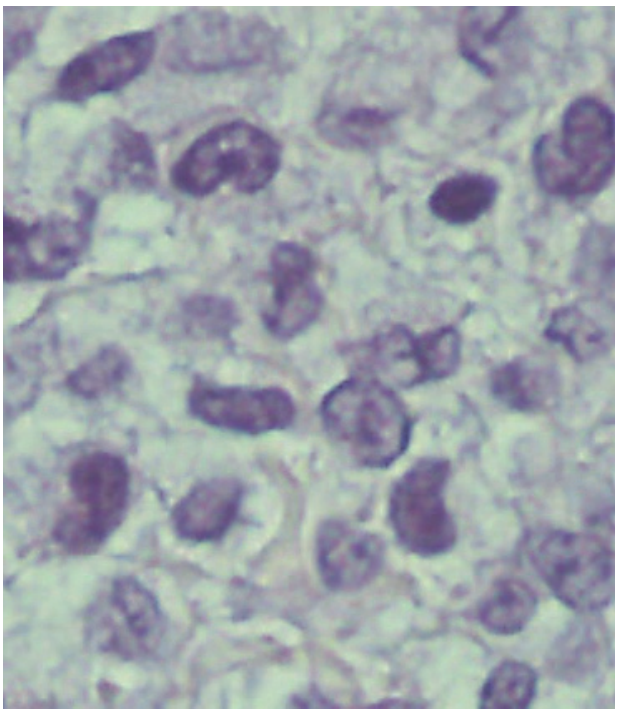

(c)

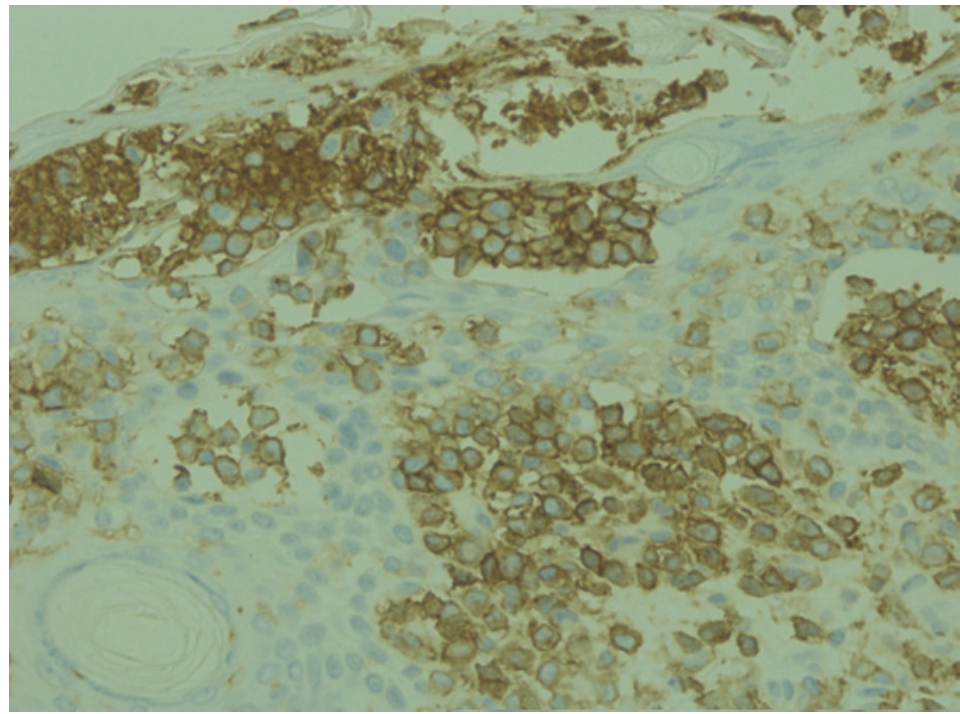

(b)

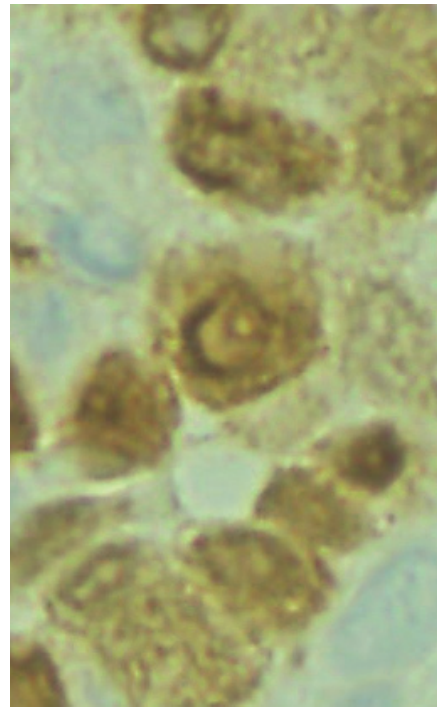

(d)

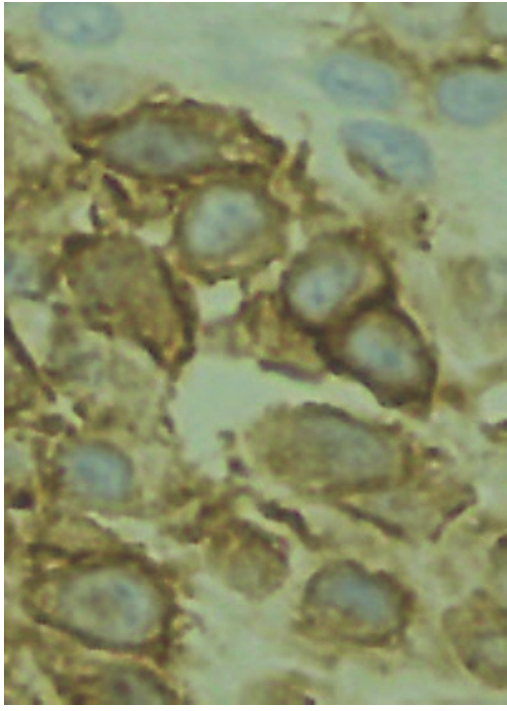

(e)

FIGURE 2: Histopathology of a cutaneous lesion showing histiocytic cell infiltration in the epidermis and dermis as well as under the stratum corneum ((a); HE stain), which were stained positive for CDla (b) (original magnification, $\times 400$ ), magnified photos showing characteristic folded "coffee bean" nucleus ((c); HE stain), positive S100 staining (d), and positive CD1a (e). Staining for E-cadherin and CD56 was negative (data not shown).

TABLE 1: Outcomes of premature neonates with congenital cutaneous LCH lesions at birth.

\begin{tabular}{lccccc}
\hline Author (reference number) & Gender & GA (wks) & Clinical features of LCH involvement & Outcome (survival) \\
\hline Vade et al. [10] & F & 35 & Skin, hepatosplenomegaly, pulmonary failure & Died (9 days) \\
Gee et al. [11] & M & 33 & Skin, pulmonary failure & Died (36 hrs) \\
Aviner et al. [12] & F & 32 & Skin, followed by multiorgan failure & Died (26 days) \\
Lee et al. [8] & M & 36 & Hydrops fetalis, skin, multiorgan failure & Died (12 days) \\
Cheng et al. [9] & M & 33 & Hydrops fetalis, skin, pleural effusion & Died (36 hrs) \\
Herbrüggen et al. [13] & M & 35 & Skin, at 3 months, pulmonary and thymic mass & Alive \\
Present case & F & 33 & Skin, hypovolemic shock, pulmonary failure & Died (57 hrs) \\
\hline
\end{tabular}

GA: gestational age, M: male, F: female, wks: weeks, and hrs: hours. 
unrecognized unfavorable prognostic factor in patients with multisystem, risk organ-positive LCH [15].

Because the life span tends to be very short in fatal cases, it is unknown whether there is sufficient time to consider chemotherapy for LCH. The limited time available for therapy presents challenges for the management of premature babies with congenital LCH. Regarding the biological variables affecting the outcome of LCH, expressions of E-cadherin and CD56 in $\mathrm{CD}^{+}{ }^{+}$cells may play a role. Absent expression of E-cadherin in $\mathrm{LCH}$ is thought to contribute to an aggressive clinical course [6]. CD56 expression has also been reported in cases of Langerhans cell sarcoma [16]. In our patient, E-cadherin expression was not observed, providing further evidence that the absence of E-cadherin is important for the progression of LCH lesions [17]. However, the effects of CD56 expression in $\mathrm{CD}^{+}{ }^{+}$cells have yet to be confirmed, because CD56 expression was not observed in our patient.

In summary, LCH should be considered in the differential diagnosis of disseminated and hemorrhagic vesicular cutaneous lesions in neonates. To confirm the diagnosis, prompt skin biopsy is required. It should be noted that not all congenital cutaneous lesions associated with $\mathrm{LCH}$ are benign and self-healing, and the outcome is affected by multiple factors. Particularly, premature neonates with extensive congenital cutaneous LCH may be fatal, because of associated multisystem organ involvements. In these cases immediate intensive care with $\mathrm{LCH}$-oriented therapeutic measures is necessary to improve the chance of survival.

\section{Consent}

Written informed consent was obtained from the parents for publication of this case report. The manuscript was prepared in accordance with the Declaration of Helsinki.

\section{Competing Interests}

The authors have no competing interests to declare.

\section{Acknowledgments}

The authors thank Dr. Taro Maeda (Shiso Municipal Hospital) for referring the patient and Drs. Tomomi Hayase and Akira Morimoto (Jichi Medical University) for performing the assay for the BRAF mutation.

\section{References}

[1] D. J. Zinn, R. Chakraborty, and C. E. Allen, "Langerhans cell histiocytosis: emerging insights and clinical implications," Oncology, vol. 30, no. 2, pp. 122-132, 2016.

[2] O. Abla and S. Weitzman, "Treatment of Langerhans cell histiocytosis: role of BRAF/MAPK inhibition," Hematology, vol. 2015, no. 1, pp. 565-570, 2015.

[3] M. Aricò, "Langerhans cell histiocytosis in children: from the bench to bedside for an updated therapy," British Journal of Haematology, vol. 173, no. 5, pp. 663-670, 2016.

[4] H. Isaacs Jr., "Fetal and neonatal histiocytoses," Pediatric Blood and Cancer, vol. 47, no. 2, pp. 123-129, 2006.
[5] K. Hashimoto, G. F. Bale, H. K. Hawkins, C. Langston, and M. S. Pritzker, "Congenital self-healing reticulohistiocytosis (Hashimoto-Pritzker type)," International Journal of Dermatology, vol. 25, no. 8, pp. 516-523, 1986.

[6] M. Lucioni, G. Beluffi, L. Bandiera et al., "Congenital aggressive variant of Langerhans cells histiocytosis with CD56+/ECadherin-phenotype," Pediatric Blood and Cancer, vol. 53, no. 6, pp. 1107-1110, 2009.

[7] C. Goñi-Orayen, R. Ruiz-Cano, A. Pérez-Martínez, E. EscarioTravesedo, M. Atienzar-Tobarra, and A. Martínez-Gutiérrez, "A fatal case of congenital disseminated Langerhans cell histiocytosis," Journal of Perinatal Medicine, vol. 27, no. 3, pp. 228-230, 1999.

[8] C. H. Lee, T. K. Lau, K. F. To, H. S. Lam, A. W. H. Chan, and P. C. Ng, "Congenital systemic Langerhans cell histiocytosis presenting as hydrops fetalis," Acta Paediatrica, vol. 94, no. 12, pp. 1843-1847, 2005.

[9] I. Cheng, Y.-L. Chen, Y.-L. Tsai, Y.-Y. Chou, T.-C. Sung, and S.-C. Mu, "Is Langerhans cell histiocytosis complicated with hydrops fetalis exclusively lethal in premature neonates?" Pediatric Dermatology, vol. 28, no. 4, pp. 469-471, 2011.

[10] A. Vade, A. Hayani, and K. L. Pierce, "Congenital histiocytosis X," Pediatric Radiology, vol. 23, no. 3, pp. 181-182, 1993.

[11] S. N. Gee, J. T. Huang, B. A. Schmidt, and S. E. Gellis, "Rapidly fatal multiorgan Langerhans cell histiocytosis in a neonate," Pediatric Dermatology, vol. 30, no. 5, pp. e85-e86, 2013.

[12] S. Aviner, M. Ronen, D. London, A. Tobar, and S. Zangen, "Langerhans cell histiocytosis in a premature baby presenting with skin-isolated disease: case report and literature review," Acta Paediatrica, vol. 97, no. 12, pp. 1751-1754, 2008.

[13] H. Herbrüggen, K. Lakatos, H. Gadner, and M. Minkov, "Isolated cutaneous Langerhans cell histiocytosis in a premature baby: what is the optimal approach?" Pediatric Blood and Cancer, vol. 60, no. 1, pp. 163-164, 2013.

[14] H. Isaacs Jr., "Cutaneous metastases in neonates: a review," Pediatric Dermatology, vol. 28, no. 2, pp. 85-93, 2011.

[15] M. Aricò, I. Astigarraga, J. Braier et al., "Lack of bone lesions at diagnosis is associated with inferior outcome in multisystem Langerhans cell histiocytosis of childhood," British Journal of Haematology, vol. 169, no. 2, pp. 241-248, 2015.

[16] T. Kawase, M. Hamazaki, M. Ogura et al., "CD56/NCAMpositive Langerhans cell sarcoma: a clinicopathologic study of 4 cases," International Journal of Hematology, vol. 81, no. 4, pp. 323-329, 2005.

[17] F. Geissmann, J. F. Emile, P. Andry et al., "Lack of expression of E-cadherin is associated with dissemination of Langerhans' cell histiocytosis and poor outcome," Journal of Pathology, vol. 181, no. 3, pp. 301-304, 1997. 


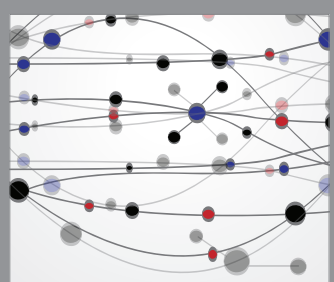

The Scientific World Journal
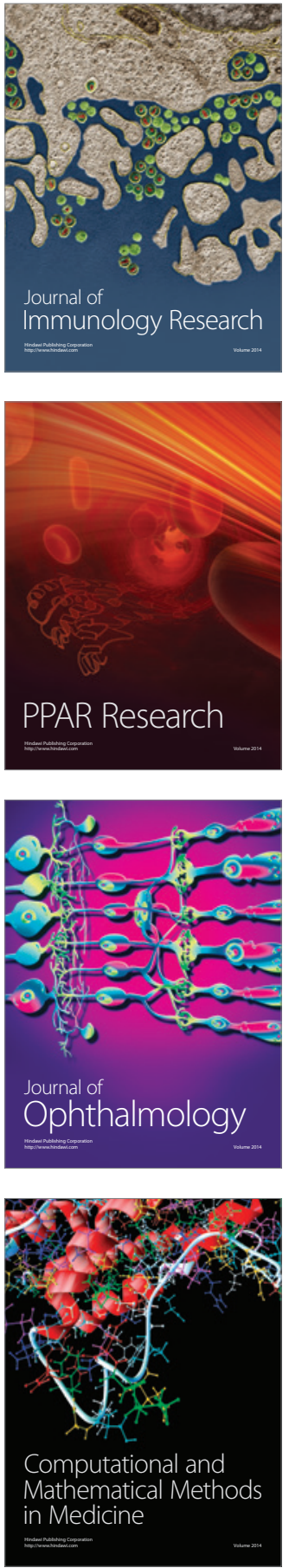

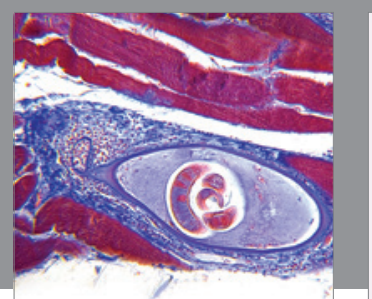

Gastroenterology Research and Practice

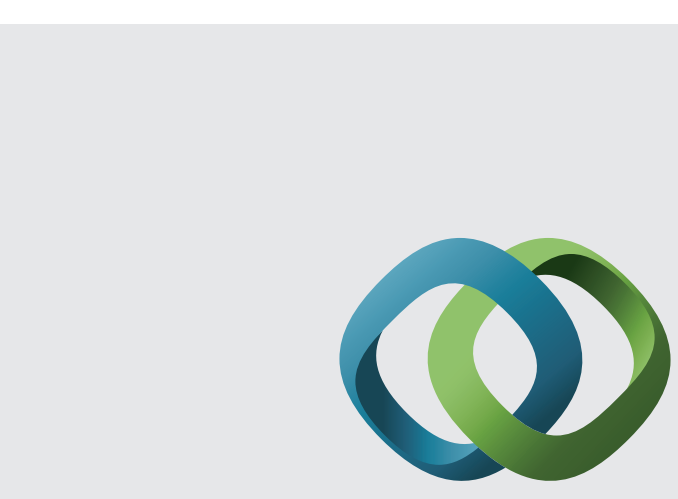

\section{Hindawi}

Submit your manuscripts at

http://www.hindawi.com
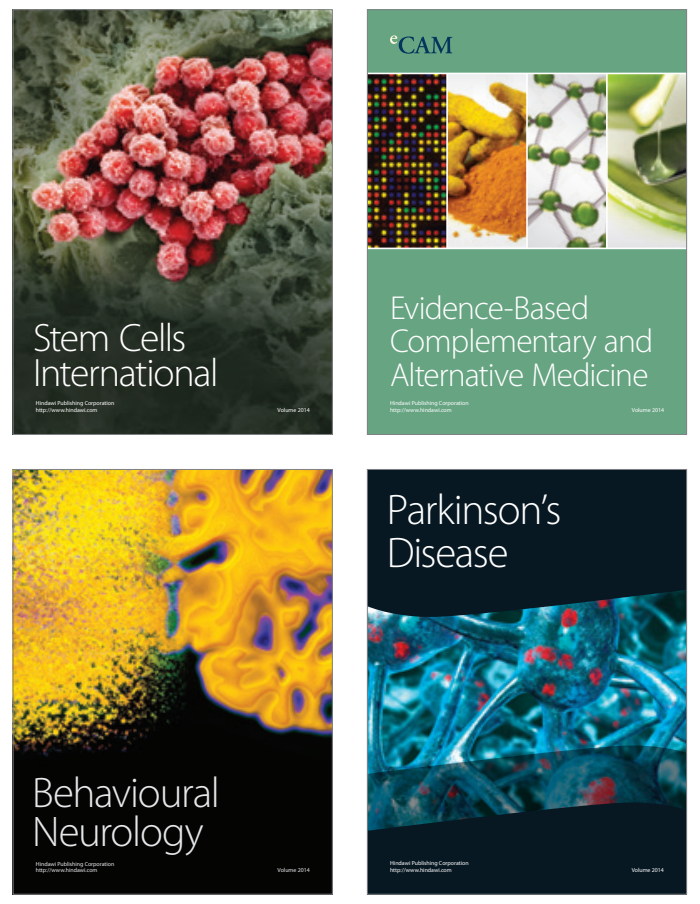
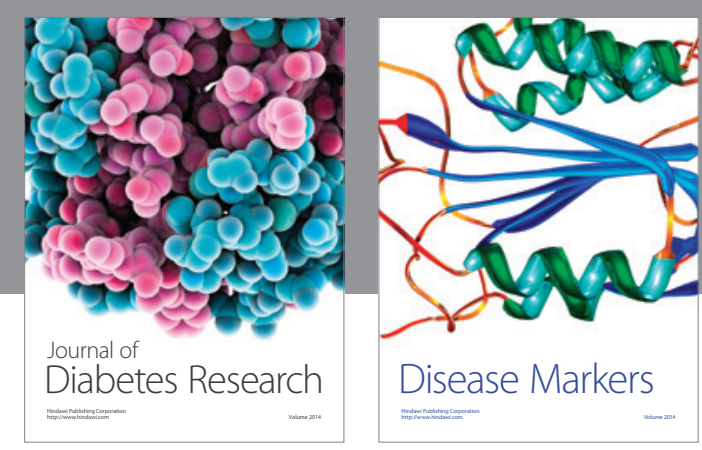

Disease Markers
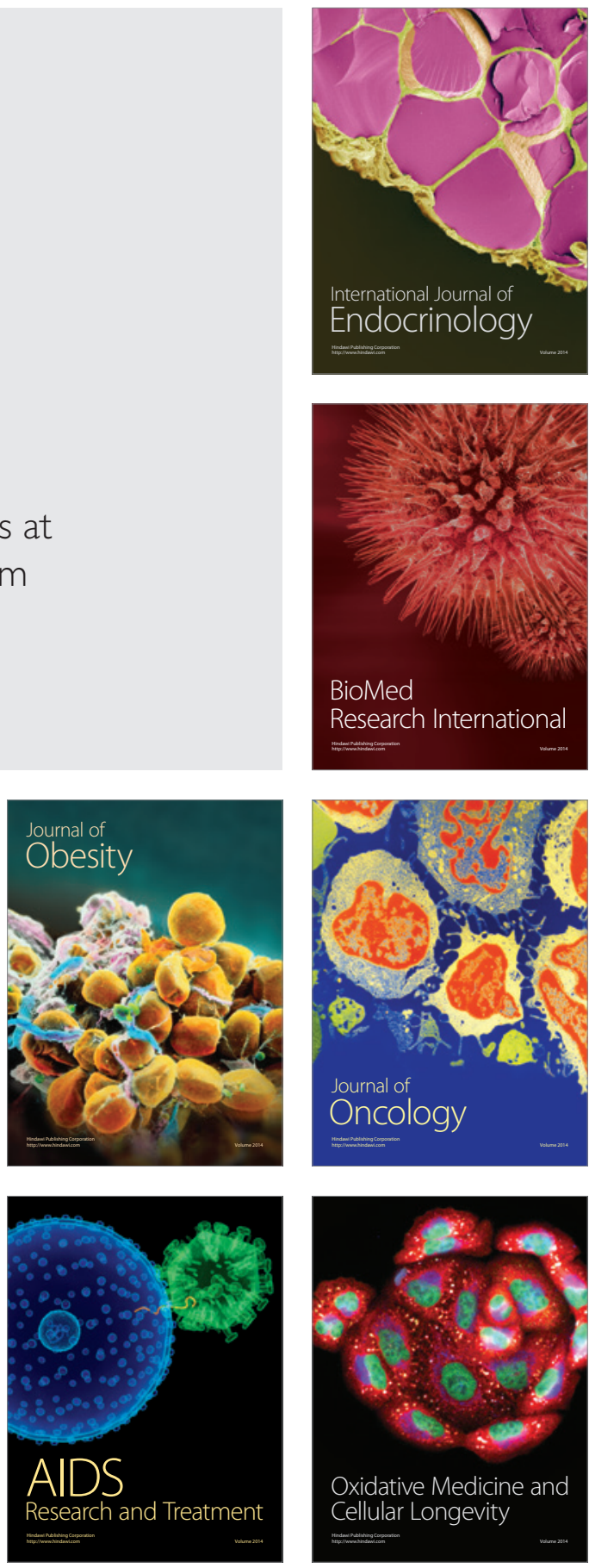